... SUPPORTING INFORMATION ...

\title{
Spontaneous Formation of Cadmium Hydroxide Nanostrands in Water
}

\author{
Izumi Ichinose, ${ }^{* \dagger}$ Keiji Kurashima, ${ }^{\dagger}$ and Toyoki Kunitake ${ }^{\ddagger}$ \\ ${ }^{\dagger}$ Advanced Materials Laboratory, National Institute for Materials Science (NIMS), 1-1 Namiki, \\ Tsukuba 305-0044, Japan, and \\ ${ }^{\ddagger}$ Frontier Research System, RIKEN, 2-1 Hirosawa, Wako 351-0198, Japan \\ E-mail: ICHINOSE.Izumi@nims.go.jp
}

The specimen for HR-TEM observation was prepared as follows. First, $20 \mathrm{~mL}$ of $4 \mathrm{mM} \mathrm{Cd}\left(\mathrm{NO}_{3}\right)_{2}$ was quickly mixed with $20 \mathrm{~mL}$ of $2 \mathrm{mM} \mathrm{NaOH}$, and aged for a few days. A copper micro grid with an about 10-nm thick carbon film was floated on this solution $(\mathrm{pH}$ 7.95) for one min, wiped with clean filter paper, and then dried in air. The observation was carried out by using a JEOL-JEM2000EX equipped a top entry specimen holder.

a)
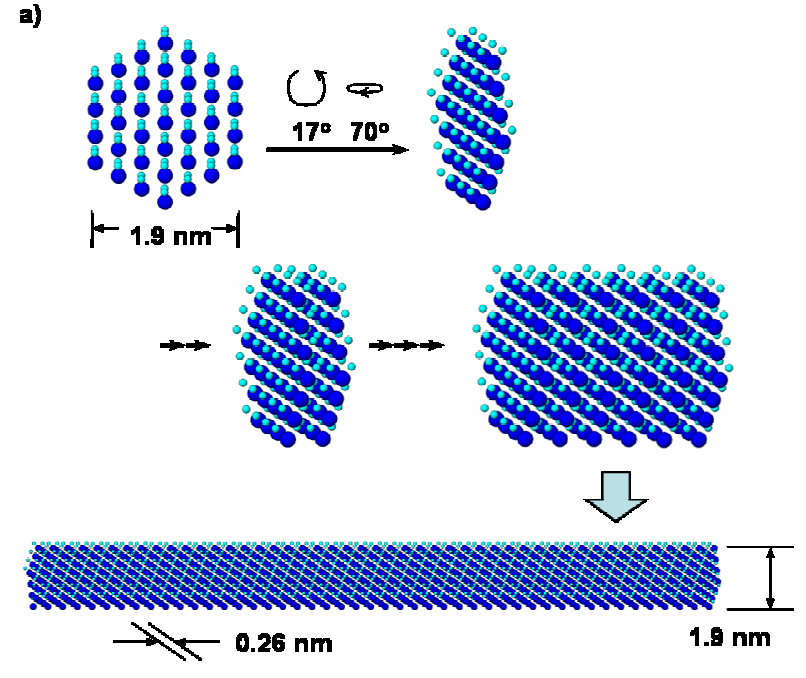

b)

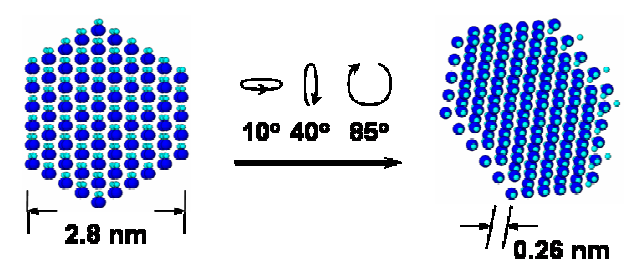

Figure S1. Structural models of cadmium hydroxide nanostrands.

The structural models of cadmium hydroxide nanostrands were calculated by means of ATOMS-V6 as follows. First, we formed a hexagonal plate, in which 37 unit cells of cadmium hydroxide (hexagonal, a: 3.496, c: 4.702, $\mathrm{P}-3 \mathrm{~m} 1)$ were arranged in a-b plane. Spatial coordinates in the unit cell are $(0.50,0.50,0.50) \mathrm{for} \mathrm{Cd},(-0.05,0.05$, $0.20)$ for $\mathrm{O}-1$, and $(0.95,0.95,0.80)$ for $\mathrm{O}-2$. Cadmium and oxygen atoms are colored blue and green, respectively. Hydrogen atoms are omitted for simplicity.

The above hexagonal plate that has a diameter of $1.9 \mathrm{~nm}$ was rotated 17 degrees in anticlockwise direction and 70 degrees in horizontal direction to give the periodicity of $0.26 \mathrm{~nm}$. Because of the tilt angle, we needed to pile up the 
hexagonal plates after shifting by one unit cell perpendicular to this sheet. The structural model calculated by this means was well consistent with the HR-TEM image.

The model for cross section (or cluster) was calculated from the two layers of a hexagonal plate composed of 75 unit cells. This probably corresponds to the nanostrand with a width of $2.8 \mathrm{~nm}$.
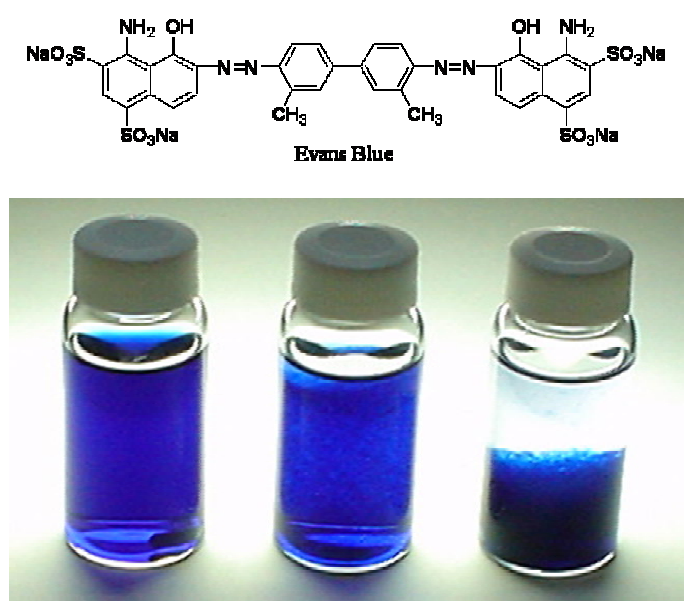

Figure S2. Photos of Evans Blue solution (left), as prepared precipitates of cadmium hydroxide nanostrands and Evans Blue (middle), and the precipitations after a few days aging (right).

Blue, weakly-gelled precipitates were formed by mixing aqueous solutions of Evens Blue and cadmium hydroxide nanostrands. The soft precipitates did not agglomerate even after a few days aging. Evans Blue does not precipitate with cadmium nitrate $\left(\mathrm{Cd}\left(\mathrm{NO}_{3}\right)_{2}\right)$ solution.

a)

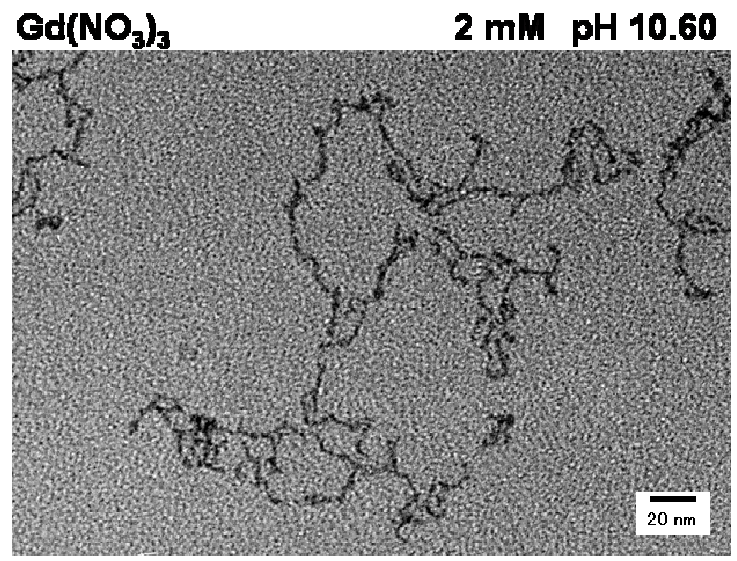

b)

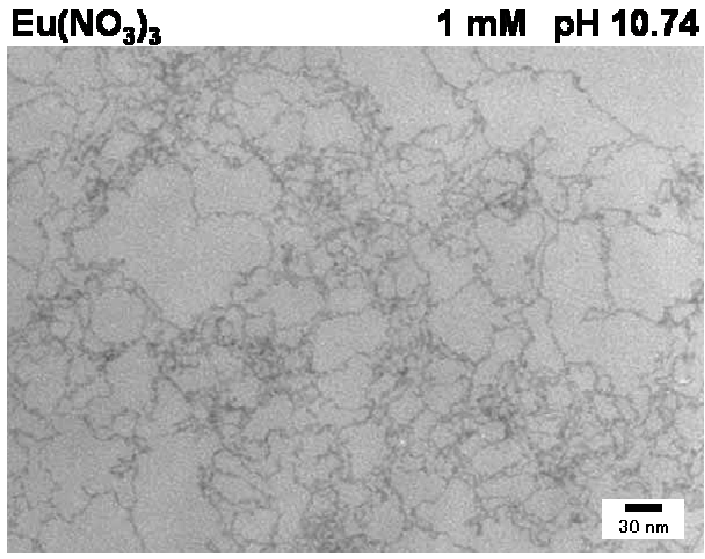

Figure S3. TEM images of lanthanide oxide nanostrands formed from aqueous solutions of $2 \mathrm{mM}$ $\mathrm{Gd}\left(\mathrm{NO}_{3}\right)_{3}$ at $\mathrm{pH} 10.60$ (a) and $1 \mathrm{mM} \mathrm{Eu}\left(\mathrm{NO}_{3}\right)_{3}$ at $\mathrm{pH} 10.74$ (b).

Very flexible nanostrands with a width of about $3 \mathrm{~nm}$ were formed in aqueous gadolinium nitrate $\left(\mathrm{Gd}\left(\mathrm{NO}_{3}\right)_{3}\right)$ and europium nitrate $\left(\mathrm{Eu}\left(\mathrm{NO}_{3}\right)_{3}\right)$ solutions after adjusting their $\mathrm{pH}$ 's near 10.5. HR-TEM observation revealed that these nanostrands were made of amorphous metal oxides. Metal oxide nanostrands are not necessary to be crystalline materials. 